\title{
Dementia, Risk, Risk Reduction, and Translation into Practice: An International Research Network for Dementia Prevention (IRNDP) Special Issue
}

\author{
Kaarin J. Anstey ${ }^{\mathrm{a}, \mathrm{b}}$ and Ruth Peters ${ }^{\mathrm{a}, \mathrm{b}, *}$ \\ ${ }^{a}$ University of New South Wales, Sydney, Australia \\ ${ }^{\mathrm{b}}$ Neuroscience Research Australia, Sydney, Australia
}

In this special issue from the International Research Network on Dementia Prevention (IRN DP), we present new research from around the globe examining the potential risk factors for dementia. We report on some of the ongoing and crucial risk reduction trials and highlight some of the population level considerations and the remaining evidence gaps. The articles on the risk factors associated with dementia range from analyses of new and established observational cohort studies [1-3] to systematic reviews [4, 5]. And from factors more recently linked to dementia risk, including poor kidney function, chronic obstructive pulmonary disease, and air pollution $[2,5,6]$ to the more established, obesity, social isolation, vascular and lifestyle factors such as diabetes or smoking $[1,4,7]$. We report protocols for two of the many ongoing trials in dementia risk reduction, the Systematic Multi-Domain Alzheimer's Risk Reduction Trial (SMARRT) [8] and the Maintain Your Brain trial [9], important adherence data from the Australian Imaging Biomarkers and Lifestyle (AIBL) active-study [10], an evaluation of an online health education tool for older adults in Malaysia [11], and some early work in mice [12]. An associated and thought provoking

\footnotetext{
*Correspondence to: Ruth Peters, Neuroscience Research Australia, Barker Street, Randwick, Sydney, NSW 2031 Australia. E-mail: r.peters@neura.edu.au.
}

editorial from Brayne and Richard raises related questions about future trial design, the intensity of intervention, and the populations to target [13]. We also begin to examine some of the gaps in the evidence and we draw attention to the lack of data across the age range and in global populations $[14,15]$. In a comprehensive umbrella review of systematic reviews, Anstey and colleagues summate the observational evidence on risk factors for Alzheimer's disease, vascular dementia, and any dementia, and highlight the lack of evidence for many risk factor exposures in midlife, a lack of data on risk factors for vascular dementia and from low and middle income countries [15]. The editorial from Glymour and Whitmer takes this further highlighting the need for a life-course understanding, and the importance of risk factor prevalence or saturation in particular populations or those with relatively small numbers (for example indigenous Australian populations) [14, 16]. Glymour and Whitmer also helpfully suggest new ways in which we can start to conceptualize, examine, and combine our data to gain the greater understanding we need for future risk reduction [14]. Finally, we report on life course and population-based approaches to dementia risk reduction. From cognitive trajectories over time in a Canadian population [17], temporal trends in incident mild cognitive impairment in the United States [18] to the implementation of demen- 
tia risk reduction policies in the United Kingdom [19] and the identification of potentially hidden cases in Japanese communities [20]. The importance of understanding the patterns of risk factor exposure, lifestyle, and available resources is also discussed and this is highlighted in particular with a comparison of population attributable risk for common risk factors in three very different Portuguese speaking countries, Portugal, Brazil, and Mozambique [21]. Sexton and Yaffe, in an associated editorial, draw together the key threads in this area. They highlight the nuanced nature of practical dementia risk reduction including the need for greater understanding at national, regional, and local levels [22].

This IRNDP issue demonstrates impressive progress in dementia prevention research and provides an invaluable collation of recent research and an up to date overview of the dementia prevention evidence base. Yet it also serves to highlight the substantial remaining evidence gaps and the next steps forward in this area of research. We have already achieved a lot but now is the time to refine and develop our understanding to be able to build the next generation of dementia risk reduction interventions with translatable and applicable policies to protect human cognitive health.

\section{DISCLOSURE STATEMENT}

Authors' disclosures available online (https:// www.j-alz.com/manuscript-disclosures/19-0506).

\section{REFERENCES}

[1] Deckers K, Nooyens A, van Boxtel M, Verhey F, Verschuren M, Köhler S (2019) Gender and educational differences in the association between lifestyle and cognitive decline over 10 years: The Doetinchem Cohort Study. J Alzheimers Dis 70, S31-S41.

[2] Cherbuin N, Walsh EI, Prina AM (2019) Chronic obstructive pulmonary disease and risk of dementia and mortality in lower to middle income countries. J Alzheimers Dis $\mathbf{7 0}$, S63-S73.

[3] Abu Bakar ZH, Damanhuri HA, Makpol S, Wan Kamaruddin WMA, Abdul Sani NF, Amir Hamzah AIZ, Nor Aripin KN, Rani MDM, Azila Noh N, Razali R, Mazlan M, Abdul Hamid H, Mohamad M, Wan Ngah WZ (2019) Effect of age on the protein profile of healthy Malay adults and its association with cognitive function competency. J Alzheimers Dis 70, S43-S62.

[4] Evans IEM, Martyr A, Collins R, Brayne C, Clare L (2019) Social isolation and cognitive function in later life: A systematic review and meta-analysis. J Alzheimers Dis $\mathbf{7 0 ,}$ S119-S144.
[5] Peters R, Ee N, Peters J, Booth A, Mudway I, Anstey KJ (2019) Air pollution and dementia: A systematic review. J Alzheimers Dis 70, S119-S144.

[6] Sacre JW, Magliano DJ, Zimmet PZ, Polkinghorne KR, Chadban SJ, Anstey KJ, Shaw JE (2019) Associations of chronic kidney disease markers with cognitive function: A 12-year follow-up study. J Alzheimers Dis 70, S19-S30.

[7] Danat IM, Clifford A, Partridge M, Zhou W, Bakre AT, Chen A, McFeeters D, Smith T, Wan Y, Copeland J, Anstey KJ, Chen R (2019) Impacts of overweight and obesity in older age on the risk of dementia: A systematic literature review and a meta-analysis. J Alzheimers Dis 70, S87-S99.

[8] Yaffe K, Barnes DE, Rosenberg D, Dublin S, Kaup AR, Ludman EJ, Vittinghoff E, Peltz CB, Renz AD, Adams KJ, Larson EB (2019) Systematic Multi-Domain Alzheimer's Risk Reduction Trial (SMARRT): Study protocol. J Alzheimers Dis 70, S207-S220.

[9] Heffernan M, Andrews G, Fiatarone Singh MA, Valenzuela M, Anstey KJ, Maeder A, McNeil J, Jorm L, Lautenschlager N, Sachdev P, Ginige A, Hobbs M, Boulamatsis C, Chau T, Cobiac L, Cox K, Daniel K, Flood VM, Guerrero Y, Gunn J, Jain N, Kochan NA, Lampit A, Mavros Y, Meiklejohn J, Noble Y, O’Leary F, Radd-Vagenas S, Walton C, Brodaty H (2019) Maintain your brain: Protocol of a 3-year randomized controlled trial of a personalized multi-modal digital health intervention to prevent cognitive decline among community dwelling 55 to 77 year olds. J Alzheimers Dis 70, S221-S237.

[10] Cox KL, Cyarto EV, Ellis KA, Ames D, Desmond P, Phal P, Sharman MJ, Szoeke C, Rowe CC, Masters CL, You E, Burrows S, Lai MMY, Lautenschlager NT (2019) A randomized controlled trial of adherence to a 24-month home-based physical activity program and the health benefits for older adults at risk of Alzheimer's disease: The AIBL ActiveStudy. J Alzheimers Dis 70, S187-S205.

[11] Vanoh D, Shahar S, Razali R, Ali NM, Abdul Manaf Z, Mohd Noah SA, Nur AM (2019) The effectiveness of a webbased health education tool, WESIHAT 2.0, among older adults: A randomized controlled trial. J Alzheimers Dis $\mathbf{7 0 ,}$ S255-S270.

[12] Wan Nasri WN, Makpol S, Mazlan M, Tooyama I, Wan Zurinah Wan Ngah WZ, Damanhuri HA (2019) Tocotrienol rich fraction supplementation modulate brain hippocampal gene expression in APPswe/PS1dE9 Alzheimer's disease mouse model. J Alzheimers Dis 70, S239-S254.

[13] Brayne C, Richard E (2019) Prevention of cognitive decline: A goal in sight? J Alzheimers Dis 70, S11-S14.

[14] Glymour MM, Whitmer RA (2019) Using cross-cultural studies to improve evidence on dementia prevention: Lessons from the special issue sponsored by the International Research Network on Dementia Prevention (IRNDP). J Alzheimers Dis 70, S5-S10.

[15] Anstey KJ, Ee N, Eramudugolla R, Jagger C, Peters R (2019) A systematic review of meta-analyses that evaluate risk factors for dementia to evaluate the quantity, quality, and global representativeness of evidence. J Alzheimers Dis $\mathbf{7 0}$, S165-S186.

[16] Radford K, Lavrencic LM, Delbaere K, Draper B, Cumming R, Daylight G, Mack HA, Chalkley S, Bennett H, Garvey G, Hill TY, Lasschuit D, Broe GA (2019) Factors associated with the high prevalence of dementia in older Aboriginal Australians. J Alzheimers Dis 70, S75-S85.

[17] McFall GP, McDermott KL, Dixon RA (2019) Modifiable risk factors discriminate memory trajectories in 
non-demented aging: Precision factors and targets for promoting healthier brain aging and preventing dementia? J Alzheimers Dis 70, S101-S118.

[18] Derby CA, Katz MJ, Rozner S, Lipton RB, Hall CB (2019) A birth cohort analysis of amnestic mild cognitive impairment incidence in the Einstein Aging Study (EAS) Cohort. J Alzheimers Dis 70, S271-S281.

[19] Collins R, Silarova B, Clare L (2019) Dementia primary prevention policies and strategies and their local implementation: A scoping review using England as a case study. J Alzheimers Dis 70, S303-S318.

[20] Meguro K, Dodge HH (2019) Vascular mild cognitive impairment: Identifying disease in community-dwelling older adults, reducing risk factors, and providing support. The Osaki-Tajiri and Kurihara Projects. J Alzheimers Dis 70, S293-S302.

[21] Oliveira D, Jun Otuyama L, Mabunda D, Mandlate F, Goncalves-Pereira M, Xavier M, Laks J, Ferri CP (2019) Reducing the number of people with dementia through primary prevention in Mozambique, Brazil, and Portugal: An analysis of population-based data. J Alzheimers Dis 70, S283-S291.

[22] Sexton CE, Yaffe K (2019) Population-based approaches to dementia prevention. J Alzheimers Dis 70, S15-S17. 